\title{
Effect of utilization of veno-venous bypass vs. cardiopul- monary bypass on complications for high level inferior vena cava tumor thrombectomy and concomitant radical nephrectomy
}

Ross M. Simon ${ }^{1}$, Timothy Kim ${ }^{2}$, Patrick Espiritu ${ }^{2}$, Tony Kurian ${ }^{1}$, Wade J. Sexton ${ }^{2}$, Julio M. Pow-Sang ${ }^{2}$, Einar Sverrisson ${ }^{2}$, Philippe E. Spiess ${ }^{2}$

${ }^{1}$ University of South Florida, Department of Urology, Tampa, FL, USA and ${ }^{2}$ Department of Genitourinary Oncology, Moffitt Cancer Center, Tampa, FL, USA

\section{ABSTRACT}

Purpose: To determine if patients with renal cell carcinoma (RCC) with levels III and IV tumor thrombi are receive any reduction in complication rate utilizing veno-venous bypass (VVB) over cardiopulmonary bypass (CPB) for high level (III/IV) inferior vena cava (IVC) tumor thrombectomy and concomitant radical nephrectomy.

Materials and Methods: From May 1990 to August 2011, we reviewed 21 patients that had been treated for RCC with radical nephrectomy and concomitant IVC thrombectomy employing either CPB $(n=16)$ or VVB $(n=5)$. We retrospectively reviewed our study population for complication rates and perioperative characteristics.

Results: Our results are reported using the validated Dindo-Clavien Classification system comparing the VVB and CPB cohorts. No significant difference was noted in minor complication rate $(60.0 \%$ versus $68.7 \%, \mathrm{P}=1.0)$, major complication rate $(40.0 \%$ versus $31.3 \%, \mathrm{P}=1.0)$, or overall complication rate $(60.0 \%$ versus $62.5 \%, \mathrm{P}=1.0)$ comparing VVB versus $\mathrm{CPB}$. We also demonstrated a trend towards decreased time on bypass $(\mathrm{P}=0.09)$ in the VVB cohort.

Conclusion: The use of VVB over CPB provides no decrease in minor, major, or overall complication rate. The use of VVB however, can be employed on an individualized basis with final decision on vascular bypass selection left to the discretion of the surgeon based on specifics of the individual case.

\section{ARTICLE INFO}

Key words:

Venae Cavae; Nephrectomy;

Neoplasms

Int Braz J Urol. 2015; 41: 911-9

Submitted for publication:

July 24,2014

Accepted after revision:

December 18, 2014

\section{INTRODUCTION}

With the increasing use of cross sectional imaging over recent years, the incidence of renal cell carcinoma (RCC) has increased at an average of $2.5 \%$ yearly (1). Although this has led to earlier detection of RCC, 5-10\% of patients continue to present with tumor thrombi formation in the inferior vena cava (IVC) at the time of diagnosis.
The presence of thrombi itself portends a poorer prognosis; however it has been demonstrated that thrombi level I-IV have equivalent 5-year cancer specific survival of 32\%-68\% after surgical intervention (1-5). Even though surgery is warranted in most patients regardless of the level of thrombus, an increased perioperative complication rate has been observed proportional to the proximal extent of the tumor thrombus. This increase in complica- 
tion rate is in part caused by the frequent need for vascular bypass to successfully resect bulky level III and IV IVC tumor thrombi (1-3, 5-9).

In an effort to reduce perioperative complications, liver transplantation techniques that do not utilize vascular bypass have been successfully applied for certain level III thrombi. However, there still exists a population of patients that cannot tolerate the decrease in cardiac return after cross clamping of the IVC, and require vascular bypass for successful resection (3,10-13). Although it is widely accepted that resection of most level IV thrombi must be accomplished with cardiopulmonary bypass (CPB), there is controversy over which type of bypass should be used for level III thrombi and selected level IV thrombi (1, 6-8, $14,15)$. In these patients the use of veno-venous bypass (VVB) has been utilized in effort to reduce the risk of perioperative coagulopathy and neurologic and systemic complications associated with CPB (4, 10-11). Most prior studies examining the use of VVB have been descriptive in nature except for a prior peer reviewed study that demonstrated decreased operative time and bypass time when compared to CPB (16). The aim of the present study was to validate this prior study's results at our own institution while taking an in-depth look at perioperative complications among RCC patients with level III or IV IVC tumor thrombi submitted to such surgery on either VVB or CPB.

\section{MATERIALS AND METHODS}

A retrospective study protocol was approved by our institutional review board prior to identifying patients at our tertiary care referral center from May 1990 to August 2011 with RCC and level III-IV IVC thrombi who underwent a radical nephrectomy and IVC thrombectomy on either VVB or CPB. Prior to their operation, a complete metastatic evaluation was conducted which included history, physical examination, and serological studies that included serum creatinine, complete blood count, calcium assessment, and liver function studies. Patients were also screened with chest X-ray or non-contrast computed tomography (CT) or magnetic resonance imaging (MRI), both with intravenous contrast when no contrain- dication was present (i.e. allergy to contrast or renal insufficiency). This was performed to assess the presence of metastases as well as differentiate the level of the tumor thrombus and carefully clinically stage patients using the American Join Committee on Cancer (AJCC, 2010) classification (17, 18). Additional tests such as bone scintigraphy were performed at the discretion of the referring urologist based on the patient's clinical presentation. The level of tumor thrombus was determined using the Mayo Classification Scale of IVC tumor thrombi $(1,18,19)$.

A retrospective chart review was performed for demographics, estimated blood loss (EBL), transfusion of packed red blood cells (PRBC), bypass pump time, operative time, anesthesia time, length of hospital stay and overall survival. Complications were also retrospectively assigned utilizing the Dindo-Clavien classification system (20). All patients with IVC tumor thrombi who did not undergo vascular bypass $(n=103)$ were excluded from the study.

Our surgical technique for resection of level III and IV IVC tumor thrombi has been previously described in the literature and is individualized based on the clinical characteristics of the patient and at the discretion of the multidisciplinary surgical team comprised of a cardiothoracic, hepatobiliary, and/or vascular surgeon (8). Most patients with Level IV thrombi underwent CPB with the exception of those patients in which the tumor thrombi could be manually migrated caudally. In patients with level III tumor thrombi we rely primarily on VVB when vascular bypass is necessary. However, in instances where level III tumor thrombi cannot be adequately controlled at the level of the suprahepatic IVC we typically utilize CPB. In either case the decision to undergo bypass is determined by our multidisciplinary team based in part on the height of the thrombus, magnitude of IVC involvement, bulk of the tumor thrombi, and the anticipated ability of the patient to tolerate cross-clamping of the IVC. After surgical resection, patients were followed routinely every 3-6 months with history and physical examination, serological testing, and radiographic imaging of the chest (chest $\mathrm{X}$-ray, non-contrast $\mathrm{CT}$ ) and abdomen (CT or MRI with intravenous contrast provided there were no contraindications). 


\section{Statistical analysis}

Estimated blood loss, intra-operative PRBC transfusions, post-operative PRBC transfusions, time on bypass, operative time, anesthesia time, length of hospital stay, overall survival (OS), disease specific survival (DSS) and complication rates were compared between the $\mathrm{CPB}$ and VVB groups. Comparisons between groups were made using Mann-Whitney U test for continuous variables and Fisher's exact test for categorical variables. The Kaplan-Meier method was used to estimate overall and disease-specific survival from the time of surgery, with comparisons made using the log-rank test. Two patients that died in the peri-operative period were omitted from the survival analysis as they died prematurely on the study. As such an intention to treat analysis was not performed. All p-values reported are two-tailed with statistical significance set when $p<0.05$. Statistical analyses were conducted using SPSS 21 (IBM Software division, Somers, NY, USA).

\section{RESULTS}

Our patient population consisted of 21 patients that had been treated by nephrectomy and concomitant IVC thrombectomy for RCC utilizing either CPB $(n=16)$ or VVB $(n=5)$. Of this group, 17 patients were classified as having level IV thrombi (81\%) and 4 were classified as having level III thrombi (19\%). The median age of the population was 64 years (43-84). Patients undergoing surgical resection had an overall good performance status, with 20 of 21(95.0\%) patients having an Eastern Cooperative Oncology Group Performance Status (ECOG PS) of 0 or 1 . The clinical and pathological characteristics of the two patient subsets (VVB and (PB) are summarized in Table- 1 .

The type of bypass utilized was not predictive of overall, minor, or major complication rate. These complication rates were determined using the validated Dindo-Clavien classification system. The overall complication rate was $60.0 \%$ in the VVB group versus $62.5 \%$ in the $\mathrm{CPB}$ group $(\mathrm{P}=1.0$, Table-2). Additionally the minor complication rate (Clavien I and II) was 60.0\% versus 68.7\% $(\mathrm{P}=1.0)$ and the major complication rate (Clavien IIIa-V) was $40.0 \%$ versus $31.3 \%(\mathrm{P}=1.0)$ in the VVB versus the $\mathrm{CPB}$ group. Notably, two perioperative mortalities occurred in the CPB group (on postoperative days 2 and 13). The death at postoperative 2 day occurred from renal insufficiency and haemothorax formation. The death at postoperative day 13 occurred from sepsis caused by an enterococcus infection. Additionally, the need for post-operative blood transfusions occurred in 0 of the VVB group and $43.8 \%$ of the $\mathrm{CPB}$ group $(\mathrm{P}=0.12)$.

Overall, we did not discover any statistical difference in the perioperative characteristics between VVB versus CPB when analyzing median EBL (2300 mL versus $3250 \mathrm{~mL}, \mathrm{P}=0.35$ ), intraoperative pRBC's transfused (6 units versus 8 units, $\mathrm{P}=0.66$ ), operative time (362 minutes versus 403 minutes, $\mathrm{P}=0.28$ ), anesthesia time (407 minutes vs. 473 minutes, $\mathrm{P}=0.18$ ), and length of hospital stay ( 8 days versus 11 days, $\mathrm{P}=0.21$ ). There was a trend however, towards decreased total time on vascular bypass in patients undergoing VVB (29 minutes versus 60 minutes, $\mathrm{P}=0.09$ ). These results are shown in Table-3.

The median post-operative follow-up for the entire population was 11.93 months (IQR: 5.59-29.92 months). The median OS for the entire population was relatively low at 16.1 months (IQR: 6.3-32.5 months) with a comparable median estimated DSS for the entire population of 20.6 months (IQR: 6.3-84.8 months). Utilization of one form of bypass over the other did not predict OS or DSS. Median OS in the VVB group was 20.6 months versus 10.16 months (IQR: 5.6-84.8) in the $\mathrm{CPB}$ group $(\mathrm{P}=0.80)$ with 2-year OS rates of 50\% (VVB) and 40\% (CPB). The overall DSS for the VVB versus the CPB group was 20.6 months (IQR: 6.3-29.9 months) versus 10.2 months (IQR 5.6-84.8 months, $\mathrm{P}=0.60$ ) with 2-year DSS rates of $50 \%$ (VVB) and (50\%).

\section{DISCUSSION}

In our current study we attempted to determine if any benefit exists in utilizing VVB over $\mathrm{CPB}$ in patients undergoing IVC tumor thrombectomy with concomitant radical nephrectomy for RCC. We assessed our surgical experience in conducting high level IVC tumor thrombi (level III 
Table 1 - Patient Clinical and Pathological Characteristics.

\begin{tabular}{|c|c|c|}
\hline Feature & $\operatorname{VVB}(n=5)$ & $\mathrm{CPB}(\mathrm{n}=16)$ \\
\hline \multicolumn{3}{|l|}{ Tumor Thrombus Level } \\
\hline Level III & $3(60.0)$ & $1(6.25)$ \\
\hline Level IV & $2(40.0)$ & $15(93.75)$ \\
\hline \multicolumn{3}{|l|}{ Age at Surgery } \\
\hline Median (Range) & $45(43-83)$ & $65(53-84)$ \\
\hline Gender M/F & $3 / 2$ & $8 / 8$ \\
\hline \multicolumn{3}{|c|}{ Extent of Disease at Time of Surgery } \\
\hline $\mathrm{N}_{+}$ & $2(40.0)$ & $5(31.25)$ \\
\hline$M_{+}$ & 0 & $5(31.25)$ \\
\hline \multicolumn{3}{|l|}{ Histologic Subtype } \\
\hline Clear Cell & $4(80.0)$ & $7(43.75)$ \\
\hline Papillary & 0 & $6(37.50)$ \\
\hline Chromophobe & 0 & 0 \\
\hline Not Specified & $1(20.0)$ & $3(18.75)$ \\
\hline \multicolumn{3}{|l|}{ Nuclear Grade } \\
\hline 1 & 0 & 0 \\
\hline 2 & $1(20.0)$ & $2(12.50)$ \\
\hline 3 & $3(60.0)$ & $4(25.00)$ \\
\hline 4 & $1(20.0)$ & $5(31.25)$ \\
\hline Not Otherwise Specified & 0 & $5(31.25)$ \\
\hline \multicolumn{3}{|l|}{ ECOG } \\
\hline 0 & $3(60.0)$ & $9(56.25)$ \\
\hline 1 & $2(40.0)$ & $6(37.50)$ \\
\hline 2 & 0 & $1(6.25)$ \\
\hline \multicolumn{3}{|l|}{ BMI } \\
\hline Median (Range) & $29.3(20.9-35.9)$ & $27.6(19.5-42.3)$ \\
\hline
\end{tabular}

$\mathbf{C P B}=$ Cardiopulmonary Bypass; $\mathbf{V V B}=$ Veno-Venous Bypass; $\mathbf{B M I}=$ Body Mass Index, RCC = Renal Cell Carcinoma; $\mathbf{M}$ = male; $\mathbf{F}=$ Female; $\mathbf{E C O G}=$ Eastern Cooperative Oncology Group Status

(Data in parenthesis are percentages)

and IV) using either VVB or CPB techniques. We have shown that both approaches can be successfully performed safely acknowledging a high peri-operative complication rate in such challenging surgical procedures for locally advanced disease.

Traditionally the use of CPB was utilized in almost all cases of level III and IV tumor thrombi. Due to the known complications of renal and hepatic failure, neurologic dysfunction, postoperative sepsis, and systemic coagulopathy associa- ted with $\mathrm{CPB}$, alternative techniques have been attempted to reduce these complications $(1,16$, 21, 22). Some level III thrombi can be successfully managed utilizing orthotopic liver transplant techniques that involves cross clamping of the IVC. This technique was reported by Cianco et al., and reduces the inherent risk associated with vascular bypass. The decrease in cardiac return after IVC cross clamping however is sometimes not tolerable in a select group of patients (Supp. Figure-1). 
Table 2 - Overall Complication Rate By Clavien Classification.

\begin{tabular}{lcc}
\hline Complication By Clavien Classification & VVB(n=5) & $\mathrm{CPB}(\mathrm{n}=16)$ \\
\hline Atrial Fibrillation II & 0 & $3(18.75)$ \\
Cephalic Vein Thrombus II & 0 & $1(6.25)$ \\
Chylous Fistula II & 0 & $1(6.25)$ \\
Deep Vein Thrombosis II & $1(20.0)$ & 0 \\
Volume Overload II & 0 & $1(6.25)$ \\
Pneumothorax IIIa & 0 & $1(6.25)$ \\
Cardiac Tamponade IIIb & 0 & $1(6.25)$ \\
Myocardial Infarction IV & $1(20.0)$ & 0 \\
Pulmonary Embolus IV & $1(20.0)$ & 0 \\
Mortality V & 0 & $2(12.5)$ \\
\hline
\end{tabular}

Data in parenthesis are percentages. $(P=1.0)$

Table 3 - Perioperative characteristics.

\begin{tabular}{lccc}
\hline Features & VVB $(\mathrm{n}=5)$ & $\mathrm{CPB}(\mathrm{n}=16)$ & P Value \\
\hline Estimated Blood Loss (mL) & $2300(1300-5200)$ & $3250(900-9000)$ & 0.35 \\
Intra-operative pRBC’s (units) & $6(4-12)$ & $8(1-38)$ & 0.66 \\
Bypass Time (min) & $34(20-50)$ & $64(16-138)$ & 0.09 \\
Operative Time (min) & $362(288-478)$ & $403(248-865)$ & 0.28 \\
Anesthesia Time (min) & $407(300-541)$ & $473(384-955)$ & 0.18 \\
Length of Hospital Stay (min) & $8(5-10)$ & $11(2-20)$ & 0.21 \\
\hline
\end{tabular}

pRBC-packed red blood cells

Data is reported as medians with range demonstrated in parentheses.

As such, the use of bypass is clearly beneficial and encouraged (Supp. Figure-2). As excessive post-operative bleeding can occur in up to $11 \%$ of patients after undergoing CPB however, VVB has been used to possibly reduce the risk of postoperative coagulopathy (24). Initially utilized for liver transplantation, VVB has the advantage that it does not require systemic anti-coagulation, as the cannulas are pre-coated with heparin $(16,22,23,25)$.

The use of VVB in IVC thrombectomy has been described extensively in the literature $(10,11$, 16, 26-29). However, only one prior retrospective study conducted by Granberg et al. has compared VVB versus CPB bypass in the setting of RCC and IVC tumor thrombi (16). This study demonstrated patients undergoing VVB $(\mathrm{n}=13)$ had significantly shorter bypass, operative, and anesthesia times than did patients treated with CPB $(n=28)$. The study also demonstrated trends towards decreased intraoperative blood loss, reduced transfusion requirements, and a shorter length of hospitalization with VVB. In our current study, we sought to perform an extensive analysis of complications while comparing similar peri-operative characteristics to the previous study. In our study we did 
Supplementary Figure 1 - Vascular control during right radical nephrectomy with inferior vena cava (IVC) thrombectomy without bypass utilizing the orthotopic liver transplant technique. Temporary clamps are placed on the hepatic hilum (hepatic artery, portal vein, and common bile duct) via the Pringle maneuver, suprahepatic IVC, infrarenal IVC, and left renal vein. If no collateral circulation exists between the suprahepatic IVC and the right atrium, decreased cardiac preload can lead to hypotension.

\section{Right Nephrectomy with IVC Thrombectomy without Bypass}

\section{Right Atrium}

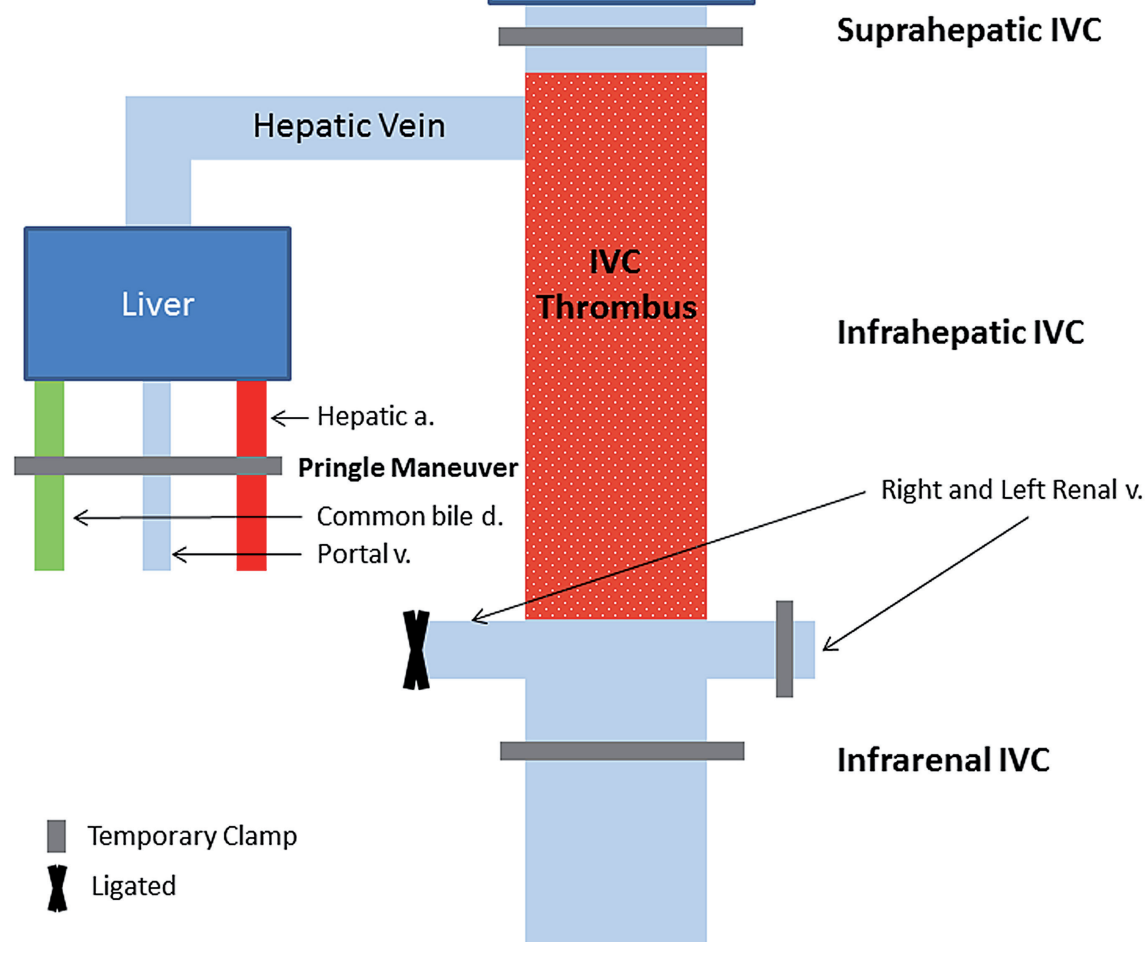

not discover trends towards decreased intraoperative blood loss, reduced transfusion requirements, and shorter length of hospital stay with the use of VVB. This could in part be from the limited power of our study or perhaps a selection bias, as any patient undergoing IVC thrombectomy for RCC is subject to substantial blood loss, leading to increased transfusion requirements, and possibly an increased hospital stay. Our study also differed from the previous, (16) as we only demonstrated a trend in decreased time on bypass and showed no statistical difference in operative time and anesthesia time. It could be assumed that since VVB only requires percutaneous access and not direct access to the vasculature like $\mathrm{CPB}$, there would be a decrease in operative and anesthesia time. However since at our institution vascular bypass is reserved for cases that require extensive mobilization and resection of the tumor thrombi, increased operative time, anesthesia time, and time on bypass would be increased in all cases (27).

Prior studies demonstrated comparable survival rates of patients with level III and IV tumor thrombi after surgical resection (5). As evidenced by our current study as well the study conducted by Granberg et al., utilizing VVB versus CPB provides no increase in OS or DSS with one form of bypass versus another. This is conceivable as both modalities allow for adequate resection of tumor thrombi and both involve a substantial and comparable insult to the cardiovascular system. As such, it is quite feasible that if the patient successfully recovers from the perioperative period, there will be no differences in intermediate long-term survival. 
Supplementary Figure 2 - Vascular control during right radical nephrectomy with inferior vena cava (IVC) thrombectomy utilizing veno-venous bypass (VVB). Similar to the orthotopic liver transplant technique, temporary clamps are placed on the hepatic hilum (hepatic artery, portal vein, and common bile duct) via the Pringle maneuver, suprahepatic IVC, infrarenal IVC, and left renal vein. Cardiac preload is restored by the bypass of the portal and venous circulation via cannulation (direction of flow depicted by arrows) of the femoral vein returning blood flow to the right atrium.

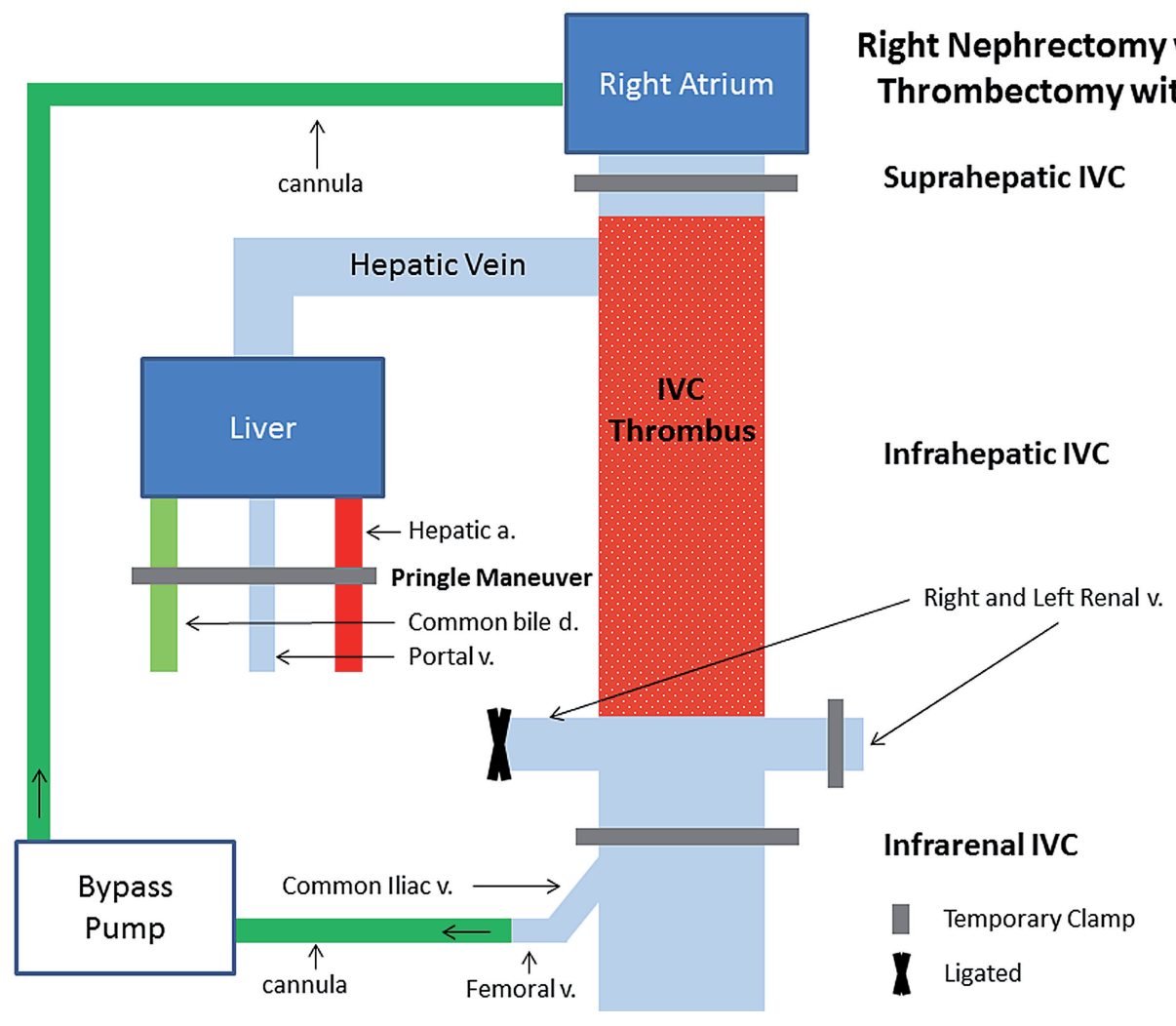

We discovered no difference in minor, major, or overall complication rate when comparing VVB versus CPB utilizing the Dindo-Clavien Classification system. Significant major complication rates (Dindo-Clavien IIIa-V) were evident in both the VVB (40.0\%) and the CPB (31.3\%) group. Notably there were two post-operative deaths (Clavien V) as well as one pneumothorax (Clavien IIIa) and one case of cardiac tamponade (Clavien IIIb) in the CPB cohort. Similarly, one intra-operative myocardial infarction (Clavien IVa) and one post-operative pulmonary embolus (Clavien IVa) occurred in the VVB group. Additionally no difference in minor complications between VVB and CPB were observed. As there is no statistical difference in minor, major, or overall complication rates between the VVB and
CPB groups, our study demonstrates that both modalities are associated with significant complications in the perioperative period. Although the use of VVB eliminates the use of systemic anticoagulation, this is only one variable that contributes to post-operative coagulopathy. Consumptive coagulopathy, which is caused by introducing red blood cells to foreign surfaces such as connecter tubing used in both VVB and CPB, increases the expression of tissue factor, which in turn initiates the coagulation cascade leading to consumption of coagulation factors and platelets $(23,24)$. As substantial post-operative complications can occur when using either VVB or CPB to successfully resect IVC tumor thrombi, knowledge of these complications is paramount for surgical planning and post-operative management. 
We acknowledge that our study is limited by its relatively small sample size as well as our single-institution retrospective design. We also acknowledge an inherent selection bias in our study as we utilize a multidisciplinary decision making process and not specific criteria to determine which patients undergo VVB versus CPB. However, in light of this, our study does not necessarily support the use of VVB over CPB in the setting of IVC thrombectomy. As both methods have similar survival and complication rates, the select use of VVB could be employed on high level thrombi (III/IV) on an individualized basis.

\section{CONCLUSIONS}

It has been speculated that the use of VVB could potentially mitigate complications associated with CPB in patients with tumor thrombi undergoing IVC thrombectomy and radical nephrectomy for RCC. However, our study demonstrated that no decrease in complication rate exists with VVB, and that both modalities come with considerable complications that must acknowledged for surgical planning as well as patient education. Although there is no clear-cut benefit to VVB, we discovered a trend of decreased time on bypass, which would possibly be significant in a larger multi-center study. We suggest that $\mathrm{CPB}$ is still a valid method for assisting in resection of level III and IV tumor thrombi in patients with RCC, however the use VVB could also be considered on an individualized basis at the discretion of the multi-disciplinary surgical team.

\section{SUPPORT/FINANCIAL DISCLOSURES}

\author{
Patrick Espiritu, MD - Employee (Moffitt \\ Cancer Center) \\ Wade J. Sexton, MD - Employee (Moffitt \\ Cancer Center) \\ Julio M. Pow-Sang, MD - Employee (Moffitt \\ Cancer Center) \\ Philippe E. Spiess, MD - Employee (Moffitt \\ Cancer Center)
}

\section{REFERENCES}

1. Blute ML, Leibovich BC, Lohse CM, Cheville JC, Zincke H. The Mayo Clinic experience with surgical management, complications and outcome for patients with renal cell carcinoma and venous tumour thrombus. BJU Int. 2004;94:33-41.

2. Chowdhury UK, Mishra AK, Seth A, Dogra PN, Honnakere $\mathrm{JH}$, Subramaniam GK, et al. Novel techniques for tumor thrombectomy for renal cell carcinoma with intraatrial tumor thrombus. Ann Thorac Surg. 2007;83:1731-6.

3. Kaag MG, Toyen C, Russo P, Cronin A, Thompson RH, Schiff $J$, et al. Radical nephrectomy with vena caval thrombectomy: a contemporary experience. BJU Int. 2011;107:1386-93.

4. Manassero F, Mogorovich A, Di Paola G, Valent F, Perrone V, Signori S, et al. Renal cell carcinoma with caval involvement: contemporary strategies of surgical treatment. Urol Oncol. 2011;29:745-50.

5. Staehler G, Brkovic D. The role of radical surgery for renal cell carcinoma with extension into the vena cava. J Urol. 2000;163:1671-5.

6. Ali AS, Vasdev N, Shanmuganathan S, Paez E, Dark JH, Manas D, et al. Thomas DJ. The surgical management and prognosis of renal cell cancer with IVC tumor thrombus: 15-years of experience using a multi-specialty approach at a single UK referral center. Urol Oncol. 2013;31:1298-304.

7. Kaplan S, Ekici S, Doğan R, Demircin M, Ozen H, Paşaoğlu I. Surgical management of renal cell carcinoma with inferior vena cava tumor thrombus. Am J Surg. 2002;183:292-9.

8. Lawindy SM, Kurian T, Kim T, Mangar D, Armstrong PA, Alsina $A E$, et al. Important surgical considerations in the management of renal cell carcinoma (RCC) with inferior vena cava (IVC) tumour thrombus. BJU Int. 2012;110:926-39.

9. Karnes RJ, Blute ML. Surgery insight: management of renal cell carcinoma with associated inferior vena cava thrombus. Nat Clin Pract Urol. 2008;5:329-39.

10. Ciancio G, Livingstone AS, Soloway M. Surgical management of renal cell carcinoma with tumor thrombus in the renal and inferior vena cava: the University of Miami experience in using liver transplantation techniques. Eur Urol. 2007;51:988-94; discussion 994-5.

11. Ciancio G, Vaidya A, Savoie M, Soloway M. Management of renal cell carcinoma with level III thrombus in the inferior vena cava. J Urol. 2002;168:1374-7.

12. Delis S, Dervenis C, Lytras D, Avgerinos C, Soloway M, Ciancio $G$. Liver transplantation techniques with preservation of the natural venovenous bypass: effect on surgical resection of renal cell carcinoma invading the inferior vena cava. World J Surg. 2004;28:614-9. 
13. Parekh DJ, Cookson MS, Chapman W, Harrell F Jr, Wells N, Chang SS, et al. Renal cell carcinoma with renal vein and inferior vena caval involvement: clinicopathological features, surgical techniques and outcomes. J Urol. 2005;173:1897-902.

14. Dominik J, Moravek P, Zacek P, Vojacek J, Brtko M, Podhola $\mathrm{M}$, et al. Long-term survival after radical surgery for renal cell carcinoma with tumour thrombus extension into the right atrium. BJU Int. 2013;111:E59-64.

15. Shuch B, Crispen PL, Leibovich BC, Larochelle JC, Pouliot F, Pantuck AJ, et al. Cardiopulmonary bypass and renal cell carcinoma with level IV tumour thrombus: can deep hypothermic circulatory arrest limit perioperative mortality? BJU Int. 2011;107:724-8.

16. Granberg CF, Boorjian SA, Schaff HV, Orszulak TA, Leibovich BC, Lohse CM, et al. Cheville JC, Blute ML. Surgical management, complications, and outcome of radical nephrectomy with inferior vena cava tumor thrombectomy facilitated by vascular bypass. Urology. 2008;72:148-52.

17. Edge SB, Byrd DR, Compton CC eds. AJCC Cancer Staging Manual, 7th edn. New York: Springer, 2010.

18. Neves RJ, Zincke H. Surgical treatment of renal cancer with vena cava extension. Br J Urol. 1987;59:390-5.

19. Fuhrman SA, Lasky LC, Limas C. Prognostic significance of morphologic parameters in renal cell carcinoma. Am J Surg Pathol. 1982;6:655-63.

20. Dindo D, Demartines N, Clavien PA. Classification of surgical complications: a new proposal with evaluation in a cohort of 6336 patients and results of a survey. Ann Surg. 2004;240:205-13.

21. Novick AC, Kaye MC, Cosgrove DM, Angermeier K, Pontes JE, Montie JE, et al. Streem SB, Klein E, Stewart R, Goormastic M. Experience with cardiopulmonary bypass and deep hypothermic circulatory arrest in the management of retroperitoneal tumors with large vena caval thrombi. Ann Surg. 1990;212:472-6; discussion 476-7.

22. Boorjian SA, Sengupta S, Blute ML. Renal cell carcinoma: vena caval involvement. BJU Int. 2007;99:1239-44.
23. Gurusamy KS, Koti R, Pamecha V, Davidson BR. Venovenous bypass versus none for liver transplantation. Cochrane Database Syst Rev. 2011;3:CD007712.

24. Johansson PI, Sølbeck S, Genet G, Stensballe J, Ostrowski SR. Coagulopathy and hemostatic monitoring in cardiac surgery: an update. Scand Cardiovasc J. 2012;46:194-202.

25. Ostermann ME, Taube D, Morgan CJ, Evans TW. Acute renal failure following cardiopulmonary bypass: a changing picture. Intensive Care Med. 2000;26:565-71.

26. Skinner DG, Pritchett TR, Lieskovsky G, Boyd SD, Stiles QR. Vena caval involvement by renal cell carcinoma. Surgical resection provides meaningful long-term survival. Ann Surg. 1989;210:387-92; discussion 392-4.

27. Browning AJ, Eardley I, Joyce AD, Minhas S, Bellamy MC. Percutaneous veno-venous bypass in surgery for renal cell carcinoma with associated vena caval tumour thrombus. BJU Int. 1999;83:850-2.

28. Baumgartner F, Scott R, Zane R, Gelman J, Rajfer J, Ages B, et al. Modified venovenous bypass technique for resection of renal and adrenal carcinomas with involvement of the inferior vena cava. Eur J Surg. 1996;162:59-62.

29. Ciancio G, Soloway MS. Renal cell carcinoma with tumor thrombus extending above diaphragm: avoiding cardiopulmonary bypass. Urology. 2005;66:266-70.

Correspondence address: Philippe E. Spiess, MD Associate Member Department of Genitourinary Oncology Moffitt Cancer Center 12902 Magnolia Dr. Tampa, FL 33612, USA Fax: + 1813 745-8494

E-mail: philippe.spiess@moffitt.org 